\title{
Lipoproteins and their subfractions in psoriatic arthritis: identification of an atherogenic profile with active joint disease
}

\author{
S M Jones, C P D Harris, J Lloyd, C A Stirling, J P D Reckless, N J McHugh
}

\begin{abstract}
Objectives-(a) To characterise the lipid profile in psoriatic arthritis and investigate whether there are similarities to the dyslipoproteinaemia reported in rheumatoid arthritis and other inflammatory forms of joint disease; $(b)$ to investigate whether there is an atherogenic lipid profile in psoriatic arthritis, which may have a bearing on mortality.

Methods-Fasting lipids, lipoproteins, and their subfractions were measured in 50 patients with psoriatic arthritis and their age and sex matched controls.

Results-High density lipoprotein cholesterol (HDL cholesterol) and its third subfraction, $\mathrm{HDL}_{3}$ cholesterol, were significantly reduced and the most dense subfraction of low density lipoprotein (LDL), $\mathrm{LDL}_{3}$, was significantly increased in the patients with psoriatic arthritis. Twenty patients with active synovitis had significantly lower total cholesterol, LDL cholesterol, and $\mathrm{HDL}_{3}$ cholesterol than their controls. $25 \%$ of the patients with psoriatic arthritis had raised $L p(a)$ lipoprotein levels (>300 mg/1) compared with $19 \%$ of controls, but this was not statistically significant.

Conclusion-Raised levels of $\mathrm{LDL}_{3}$ and low levels of HDL cholesterol are associated with coronary artery disease. Such an atherogenic profile in a chronic inflammatory form of arthritis is reported, which may be associated with accelerated mortality.

(Ann Rheum Dis 2000;59:904-909)
\end{abstract}

Rheumatic Diseases,

Trim Bridge, Bath

BA1 1HD, UK

$\mathrm{S} \mathrm{M}$ Jones

N J McHugh

Diabetes and Lipid

Research Group,

Wolfson Centre, Royal

United Hospital, Bath,

UK

C P D Harris

J Lloyd

C A Stirling

J P D Reckless

Correspondence to:

Dr S M Jones, Consultant

Rheumatologist, University

Hospital of Wales, Heath

Park, Cardiff, Wales

Email:

sharon.jones@:uhw-tr.wales. nhs.uk

Accepted for publication 10 April 2000

Patients with rheumatoid arthritis (RA) have an accelerated mortality compared with the general population, which may be attributed in part to an increased risk of cardiovascular disease. ${ }^{1}$ Active RA is associated with an abnormal lipid profile (dyslipidaemia), though the relative contribution of this to the increased mortality is uncertain. Altered concentrations of serum ${ }^{2-6}$ and synovial lipids ${ }^{7}$ and lipoproteins may occur, including reduced serum cholesterol, ${ }^{2}$ decreased serum triglycerides, ${ }^{3-6}$ and altered apoprotein concentrations. ${ }^{3}$ In addition, decreased cholesterol in low density lipoprotein (LDL), and cholesterol in high density lipoprotein (HDL) have been found, especially in association with active disease. ${ }^{4}$ The causes of mortality in patients with psoriatic arthritis are less well documented, though there is evidence that mortality may be increased. ${ }^{8} \mathrm{~A}$ pattern of dyslipoproteinaemia, similar to that seen in RA, has previously been reported in psoriatic arthritis, which normalises with a reduction in disease activity. ${ }^{5}$

Routine plasma lipid measurement, which does not take account of lipoprotein composition, may not identify patients with risk factors for atherosclerosis. For instance, a reduction in HDL cholesterol contributes to a risk of atheroma, whereas a concomitant reduction in total LDL cholesterol may be protective. In population studies a low HDL cholesterol associated with a high LDL cholesterol has been associated with an increased risk of atherosclerosis. ${ }^{9}$ Increased knowledge of lipoprotein composition, and the identification of lipoprotein subfractions, have added to our understanding of the mechanisms of metabolic disturbance in lipid disorders. ${ }^{10}$ It is now well established that the smallest, most dense component of LDL ( $\mathrm{LDL}_{3}$ in our study), is the most important factor in contributing to atheroma. ${ }^{11}$

$\mathrm{Lp}$ (a) lipoprotein has emerged as an important and independent contributing factor to the risk of artherosclerosis. ${ }^{12-14}$ It is a high density lipoprotein in which apoprotein B 100, the protein moiety of LDL, is linked to apoprotein(a) by one or two disulphide bridges. Increased levels of $\mathrm{Lp}$ (a) lipoprotein have been found in RA, but have not previously been measured in psoriatic arthritis. ${ }^{15}$ In this study we performed a detailed analysis of lipoprotein composition in psoriatic arthritis and found changes that may lead to increased atherosclerosis and shortened survival.

\section{Patients and methods}

PATIENTS AND CONTROLS

Fifty patients attending the psoriatic arthritis matic Diseases were studied. Twenty of these patients had active joint disease, and LDL and very low density lipoprotein (VLDL) subfraction data were obtained for 13 of these. All patients had psoriasis, an inflammatory arthropathy, and were seronegative for rheumatoid factor. Age and sex matched controls were obtained from a concurrent local population survey. Table 1 shows demographic details for both patients and controls. The exclusion criteria for patients and controls were diabetes, hypothyroidism, renal disease, excess alcohol intake, current treatment with a lipid lowering agent, admission to hospital with a severe illness within the previous three months, pregnancy, and breast feeding. Excess alcohol intake was defined as an intake of greater than the recommended upper limit for alcohol consumption for men and women (28 units for 
Table 1 Clinical details of 50 patients and controls with specific reference to factors known to affect lipids

\begin{tabular}{lll}
\hline Factor & Patient & Control \\
\hline Mean age (years, range) & $44.8(20-72)$ & $44.8(20-72)$ \\
Sex (M/F) & $21 / 29$ & $21 / 29$ \\
Mean body mass index (SD) & $25.8(5.6)$ & $24.6(4.7)$ \\
PASI^ score (mean, range) & $3.3(0-8.7)$ & 0 \\
Subgroup of joint disease (number of patients) & \\
$\quad$ Oligoarthritis & 21 & 0 \\
$\quad$ Polyarthritis & 27 & 0 \\
Mutilans & 1 & 0 \\
Spondylitis & 1 & 0 \\
History of gout & 0 & 4 \\
Topical dovanex & 1 & 0 \\
NSAIDs & 48 & 0 \\
Oral contraceptive & 0 & 5 \\
Hormone replacement therapy & 0 & 7 \\
Antihypertensive drugs & & \\
$\quad$ B Blockers & 1 & 1 \\
Thiazides & 1 & 1
\end{tabular}

No patient or control had concurrent infection, malignancy, ischaemic heart disease, liver disease or was taking corticosteroids or retinoids.

${ }^{\star}$ PASI $=$ psoriasis area and severity index; NSAIDs = non-steroidal anti-inflammatory drugs.

men and 21 units for women). Any other concurrent or previous illness known to affect the lipid profile (infection, malignancy, gout, ischaemic heart disease, or liver disease) was recorded. Four patients in the control group had a history of gout but were not hyperuricaemic at the time of the study.

Present and previous drugs were noted for all patients, particularly oral corticosteroids, retinoids, thiazides, $\beta$ blockers, oral contraceptives, and hormone replacement therapy. Five of the control group were taking oral contraceptives and seven hormone replacement therapy. None of the controls for the 13 patients on whom LDL and VLDL subfractions were measured were taking hormone replacement therapy.

All patients and controls were eating a normal Western diet. Body mass indices $\left(\mathrm{kg} / \mathrm{m}^{2}\right)$ were calculated for all patients. Blood samples were taken from all patients after a 14 hour fast, centrifuged within two hours of collection, and kept at $-20^{\circ} \mathrm{C}$ until analysis. Samples for ultracentrifugation were analysed immediately.

\section{ASSESSMENT OF DISEASE ACTIVITY}

The inflammatory markers, plasma viscosity, erythrocyte sedimentation rate (ESR), and C reactive protein (CRP) were measured in all patients. Active disease was defined as at least one clinically inflamed joint in association with a raised ESR ( $>20 \mathrm{~mm} / 1 \mathrm{st} \mathrm{h}$ ) and/or viscosity $(>1.72 \mathrm{mPa})$, and/or CRP (>10 mg/l). The psoriasis area and severity index (PASI) were used to record the severity and activity of skin disease. ${ }^{16}$

MEASUREMENT OF LIPOPROTEINS

Automated measurements were performed using an Abbott VP supersystem autoanalyser (Abbott Diagnostic Division, Maidenhead, UK). Lipids and lipoproteins were measured by standard precipitation techniques. Briefly, VLDL, total HDL, and its third, most dense subfraction $\left(\mathrm{HDL}_{3}\right)$ were prepared by precipitation with sodium dodecyl sulphate, heparinmanganese chloride, and dextran sulphate respectively. Cholesterol and triglyceride were measured in these subfractions by cholesterol oxidase $p$-amino-antipyrene and glycerol phosphate oxidase $p$-amino-antipyrene enzymatic calorimetric methods (Boehringer, Mannheim, Germany) (interassay coefficients of variation (CV) $4 \%$ and $5 \%$, and intra-assay CV $3 \%$ and $2 \%$ respectively). $\mathrm{HDL}_{2}$ (density $1.063-1.125$ $\mathrm{g} / \mathrm{ml}$ ) was calculated by subtraction of $\mathrm{HDL}_{3}$ (density $1.125-1.210 \mathrm{~g} / \mathrm{ml}$ ) from total HDL. LDL cholesterol and LDL triglyceride were calculated by subtraction of the directly measured HDL and VLDL fractions from total serum cholesterol and triglyceride.

Apolipoprotein A I and apolipoprotein B were measured by electroimmunodiffusion in agarose gel (Sebia, Issy-les-Moulineaux, France). Lp(a) lipoprotein was measured in 45 patients by enzyme linked immunosorbent assay (ELISA) (TintElize Lp(a) lipoprotein, Biopool, Sweden: Box 1454, S-901 24 Umea) (assay range $0-800 \mathrm{mg} / \mathrm{l}$ ).

MEASUREMENT OF LIPOPROTEIN SUBFRACTIONS In 13 patients (nine female, four male) with active psoriatic arthritis randomly selected from the total patient group and 13 age and sex matched healthy volunteers, blood samples were fractionated by cumulative flotation ultracentrifugation as described by Lindgren et al. ${ }^{9}$ Briefly, plasma was adjusted to a density of $1.118 \mathrm{~g} / \mathrm{ml}$ by adding solid sodium chloride $(\mathrm{NaCl})$. Density adjusted plasma $(2 \mathrm{ml})$ was layered onto the surface of $0.5 \mathrm{ml}$ of a $\mathrm{NaCl} /$ sodium bromide solution (density 1.182 $\mathrm{g} / \mathrm{ml}$ ) in an ultracentrifuge tube. Solutions with the following densities were layered onto the surface of the plasma: $1 \mathrm{ml}$ of $1.0988 \mathrm{~g} / \mathrm{ml}$ followed by $1 \mathrm{ml}$ of $1.086 \mathrm{~g} / \mathrm{ml}, 2 \mathrm{ml}$ of 1.079 $\mathrm{g} / \mathrm{ml}, 2 \mathrm{ml}$ of $1.0722 \mathrm{~g} / \mathrm{ml}, 1.5 \mathrm{ml}$ of 1.0641 $\mathrm{g} / \mathrm{ml}$, and, finally, $1.5 \mathrm{ml}$ of $1.0588 \mathrm{~g} / \mathrm{ml}$. Ultracentrifugation was carried out in an SW41 Ti rotor at $23^{\circ} \mathrm{C}$. Seven consecutive runs were performed, calculated to float lipoproteins of the following flotation rates $(\mathrm{Sf}=$ Svedberg flotation units) to the top of the tube: chylomicrons $(\mathrm{Sf}>400)$, three subfractions of VLDL: $\mathrm{VLDL}_{1}$, Sf 100-400; $\mathrm{VLDL}_{2}$ : Sf

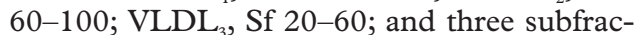
tions of LDL: $\mathrm{LDL}_{1}$, Sf 12-20; $\mathrm{LDL}_{2}$, Sf 6-12; $\mathrm{LDL}_{3}$, Sf 3-6. After each run, chylomicrons, $\mathrm{VLDL}_{1}, \mathrm{VLDL}_{2}$, and $\mathrm{VLDL}_{3}$ were aspirated from the top $0.5 \mathrm{ml}$ of the tube and $\mathrm{LDL}_{1}$, $\mathrm{LDL}_{2}$, and $\mathrm{LDL}_{3}$ were aspirated from the top $1.0 \mathrm{ml}$ of the tube, and the tube refilled with the same amount of solution of density $1.0588 \mathrm{~g} / \mathrm{ml}$. The cholesterol and triglyceride components of these subfractions were measured by the enzymatic calorimetric methods described above and automated measurements were made using the Abbott VP supersystem autoanalyser.

\section{DATA ANALYSIS}

Data were entered onto an Apple Macintosh computer and analysis was performed using paired $t$ tests for continuous variables following normality testing and the $\chi^{2}$ test for comparing proportions. Before the analysis the nonnormally distributed data, including all triglyceride fractions and ratios and the VLDL cholesterol:apolipoprotein B ratio, were loga- 
Table 2 Lipid and lipoprotein concentrations in 50 patients with psoriatic arthritis and 20 patients with active disease and their age and sex matched controls. Results are expressed as means (SEM). Statistics: $t$ test

\begin{tabular}{|c|c|c|c|c|}
\hline Lipid/lipoprotein concentration (units) & $\begin{array}{l}\text { Patients with } \\
\text { psoriatic arthritis } \\
(n=50)\end{array}$ & Controls & $\begin{array}{l}\text { Patients with active } \\
\text { disease }(n=20)\end{array}$ & Controls \\
\hline Mean age (years, range) & $44.8(20-72)$ & $44.8(20-72)$ & $42.5(20-72)$ & $42.5(20-72)$ \\
\hline Total cholesterol $(\mathrm{mmol} / \mathrm{l})$ & $5.43(0.2)$ & $5.82(0.13)$ & $4.99(0.24)^{\star \star \star}$ & $6.08(0.22)^{\star \star \star}$ \\
\hline VLDL cholesterol $(\mathrm{mmol} / \mathrm{l})$ & $0.51(0.05)$ & $0.49(0.04)$ & $0.44(0.05)$ & $0.51(0.04)$ \\
\hline LDL cholesterol $(\mathrm{mmol} / \mathrm{l})$ & $3.67(0.19)$ & $4.0(0.1)$ & $3.3(0.25)^{\star}$ & $4.12(0.25)^{\star}$ \\
\hline HDL cholesterol $(\mathrm{mmol} / \mathrm{l})$ & $1.12(0.05)^{\star}$ & $1.29(0.1)^{\star}$ & $1.09(0.05)$ & $1.33(0.1)$ \\
\hline HDL-3 cholesterol (mmol/1) & $0.62(0.04)^{\star \star \star \star}$ & $0.75(0.02)^{\star \star \star}$ & $0.62(0.1)^{\star}$ & $0.77(0.09)^{\star}$ \\
\hline HDL-2 cholesterol (mmol/l) & $0.52(0.03)$ & $0.57(0.04)$ & $0.49(0.18)$ & $0.56(0.17)$ \\
\hline Total cholesterol: HDL cholesterol & $5.40(0.34)$ & $5.14(0.47)$ & $5.30(0.65)$ & $4.86(0.33)$ \\
\hline Total triglyceride $(\mathrm{mmol} / \mathrm{l})$ & $1.15(1.09)$ & $1.13(1.07)$ & $0.99(1.14)$ & $1.35(1.1)$ \\
\hline VLDL triglyceride $(\mathrm{mmol} / \mathrm{l})$ & $0.30(1.15)$ & $0.32(1.13)$ & $0.25(1.22)$ & $0.35(1.27)$ \\
\hline LDL triglyceride $(\mathrm{mmol} / 1$ & $0.63(1.1)$ & $0.52(1.1)$ & $0.53(1.16)$ & $0.59(1.13)$ \\
\hline HDL triglyceride $(\mathrm{mmol} / \mathrm{l})$ & $0.23(1.04)$ & $0.25(1.15)$ & $0.21(1.06)$ & $0.24(1.11)$ \\
\hline Total cholesterol: total triglyceride & $4.57(1.07)$ & $5.00(1.07)$ & $4.95(1.65)$ & $4.44(1.51)$ \\
\hline VLDL cholesterol: VLDL triglyceride & $1.35(1.07)$ & $1.36(1.07)$ & $1.36(1.65)$ & $1.23(1.84)$ \\
\hline LDL cholesterol: LDL triglyceride & $5.47(2.23)^{\star \star}$ & $7.40(1.07)^{\star \star}$ & $5.75(1.86)$ & $6.69(1.49)$ \\
\hline HDL cholesterol: HDL triglyceride & $4.76(1.05)$ & $4.95(1.20)$ & $4.71(1.54)$ & $5.26(1.55)$ \\
\hline Apolipoprotein A I (mg/l) & $1370(42.2)$ & $1370(48.8)$ & $1340(42.2)$ & $1450(48.8)$ \\
\hline Apolipoprotein B (mg/l) & $800(36.8)$ & $780(58.6)$ & $710(36.8)$ & $830(58.6)$ \\
\hline Apolipoprotein A I: HDL cholesterol & $132(6.8)$ & $115(6.2)$ & $138(16.7)$ & $111(4.16)$ \\
\hline Apolipoprotein B: LDL cholesterol & $24(2.2)$ & $19.9(0.92)$ & $25(4.68)$ & $21(1.12)$ \\
\hline
\end{tabular}

Significant results for patients with psoriatic arthritis $v$ controls: ${ }^{\star} \mathrm{p}<0.05 ;{ }^{\star \star} \mathrm{p}<0.01 ;{ }^{\star \star \star} \mathrm{p}<0.005$.

$\mathrm{VLDL}=$ very low density lipoprotein; $\mathrm{LDL}=$ low density lipoprotein; HDL $=$ high density lipoprotein.

rithmically transformed for data analysis, and are given in the text and tables as antilogs. Values are presented as means (SEM) for normally distributed data or as antilogs (means (SEM)) for non-normally distributed data. The Mann-Whitney $U$ test was used for the non-parametric Lp(a) lipoprotein data. Pearson's coefficient of correlation was used for correlation analysis.

\section{Results}

CLINICAL CHARACTERISTICS

Fifty patients with psoriatic arthritis were recruited, 20 of whom met the criteria for clinically active peripheral joint disease. The patients spanned a spectrum of disease subgroups. All patients had mild skin disease only, at the time of the study, and no patient had a PASI score greater than 8.7 (table 1). There were no significant correlations between PASI scores and any lipid parameter.

The major differences in treatment between patients and controls were in the use of hormone replacement therapy (HRT) in seven of the controls, and non-steroidal anti-inflammatory drugs (NSAIDs) in all but two of the patients, which will be discussed. None of the nine female controls used in the ultracentrifuge study were taking HRT or oral contraceptives.

\section{LIPID AND LIPOPROTEIN CONCENTRATIONS}

Table 2 shows the lipid and lipoprotein results for 50 patients with psoriatic arthritis, including 20 patients with active joint disease, and their age and sex matched controls. HDL cholesterol was significantly reduced in the patients with psoriatic arthritis and the difference was related to cholesterol in $\mathrm{HDL}_{3}$. There was no difference in the mean cholesterol in $\mathrm{HDL}_{3}$ between the total group of 50 patients and those with active disease, so the significance of the difference between patients and controls was greater for the total group. Reduced total cholesterol levels were even more pronounced in the 20 patients with active synovitis who were analysed separately. Patients with active arthritis had significantly lower total cholesterol and LDL cholesterol than their controls. The relative overall influence of LDL cholesterol and HDL cholesterol was expressed by calculating the ratio of serum total cholesterol concentration to that of HDL cholesterol (table 2). The ratio tended to be higher for patients than controls in both the total patient group and those with active disease, but did not reach statistical significance.

To assess any proportional changes in cholesterol and triglyceride in patients versus controls, the ratios of total cholesterol to triglyceride and their relative proportions in each lipoprotein were analysed (table 2). For the total group of 50 patients, the cholesterol:triglyceride ratio in LDL was significantly less than in the control subjects, indicating a relative depletion of cholesterol compared with triglyceride in this lipoprotein. There was a similar trend in patients with active arthritis, though the difference did not reach significance. The total cholesterol:total triglyceride ratio and proportions of cholesterol and triglyceride in HDL tended to be lower in the patient group, but the differences were not significant. The VLDL cholesterol:VLDL triglyceride ratio was similar for patients and controls.

\section{APOLIPOPROTEINS}

For the total group there were no significant differences in the apolipoproteins A I and B in the patients with psoriatic arthritis compared with controls (table 2 ). In the 20 patients with active disease, both apolipoproteins tended to slightly lower, but this was not significant. Apolipoprotein A I is the predominant protein in HDL and apolipoprotein B the predominant protein in LDL. Therefore the apolipoprotein A I:HDL cholesterol and apolipoprotein B:LDL cholesterol ratios were calculated and compared for patients and controls. Both ratios 
Table 3 Concentration of cholesterol, triglyceride, phospoholipid, and protein of each lipoprotein subfraction and their total mass for patients with psoriatic arthritis and controls $(n=13)$. Results are expressed as means (SEM). Units $\mathrm{mg} / \mathrm{dl}$

\begin{tabular}{|c|c|c|c|c|c|c|c|c|c|c|}
\hline & \multicolumn{2}{|l|}{ Total cholesterol } & \multicolumn{2}{|l|}{ Triglyceride } & \multicolumn{2}{|l|}{ Phospholipid } & \multicolumn{2}{|l|}{ Protein } & \multicolumn{2}{|l|}{ Total mass } \\
\hline & Patient & Control & Patient & Control & Patient & Control & Patient & Control & Patient & Control \\
\hline Chylomicrons & $0.12(0.03)$ & $0.11(0.02)$ & $0.36(0.13)$ & $0.45(0.14)$ & $\begin{array}{l}0.05 \\
(0.01)^{\star}\end{array}$ & $\begin{array}{l}0.37 \\
(0.15)^{\star}\end{array}$ & $0.18(0.03)$ & $0.35(0.18)$ & $0.65(0.16)$ & $1.28(0.29)$ \\
\hline $\mathrm{VLDL}_{1}$ & $1.82(0.59)$ & $1.05(0.27)$ & $14.5(4.44)$ & $7.62(1.48)$ & $2.8(0.9)$ & $\begin{array}{l}1.06 \\
(0.2)\end{array}$ & $1.81(0.59)$ & $1.19(0.32)$ & $\begin{array}{l}20.94 \\
(6.49)\end{array}$ & $\begin{array}{l}10.92 \\
(1.99)\end{array}$ \\
\hline $\mathrm{VLDL}_{2}$ & $3.09(1.05)$ & $2.08(0.41)$ & $15.5(4.48)$ & $\begin{array}{l}11.62 \\
(2.09)\end{array}$ & $4.2(1.3)$ & $\begin{array}{l}2.46 \\
(0.33)\end{array}$ & $2.99(0.89)$ & $2.1(0.34)$ & $\begin{array}{l}30.65 \\
(18.35)\end{array}$ & $\begin{array}{l}12.38 \\
(3.03)\end{array}$ \\
\hline $\mathrm{VLDL}_{3}$ & $9.67(2.66)$ & $7.79(1.43)$ & $\begin{array}{l}20.88 \\
(4.83)\end{array}$ & $\begin{array}{l}16.38 \\
(1.94)\end{array}$ & $9.89(2.37)$ & $\begin{array}{l}7.03 \\
(1.05)\end{array}$ & $7.0(1.88)$ & $6.0(0.85)$ & $\begin{array}{l}45.22 \\
(12.04)\end{array}$ & $\begin{array}{l}35.52 \\
(3.96)\end{array}$ \\
\hline $\mathrm{LDL}_{1}$ & $13.95(1.85)$ & $15.24(1.86)$ & $9.49(1.15)$ & $7.68(0.81)$ & $9.99(1.12)$ & $\begin{array}{l}9.12 \\
(1.25)\end{array}$ & $9.56(0.9)$ & $9.03(0.97)$ & $\begin{array}{l}42.99 \\
(4.51)\end{array}$ & $41(4.51)$ \\
\hline $\mathrm{LDL}_{2}$ & $55.92(2.99)$ & $65.96(4.92)$ & $\begin{array}{l}10.77 \\
(1.33)\end{array}$ & $8.48(1.03)$ & $\begin{array}{l}34.49 \\
(3.17)\end{array}$ & $\begin{array}{l}37.59 \\
(2.95)\end{array}$ & $\begin{array}{l}39.95 \\
(1.96)\end{array}$ & $\begin{array}{l}40.99 \\
(2.66)\end{array}$ & $\begin{array}{l}142.8 \\
(9.46)\end{array}$ & $\begin{array}{l}153.6 \\
(9.97)\end{array}$ \\
\hline $\mathrm{LDL}_{3}$ & $\begin{array}{l}25.59 \\
(3.81)^{\star \star}\end{array}$ & $\begin{array}{l}14.53 \\
(0.79)^{\star \star}\end{array}$ & $\begin{array}{l}4.02 \\
(0.67)^{\star \star}\end{array}$ & $\begin{array}{l}1.92 \\
(0.23)^{\star \star}\end{array}$ & $\begin{array}{l}13.98 \\
(3.39)^{\star}\end{array}$ & $\begin{array}{l}7.28 \\
(0.72)^{\star}\end{array}$ & $\begin{array}{l}20.74 \\
(3.42)^{\star}\end{array}$ & $\begin{array}{l}11.92 \\
(0.91)^{\star}\end{array}$ & $\begin{array}{l}61.9 \\
(10.61)^{\star}\end{array}$ & $\begin{array}{l}35.65 \\
(2.18)^{\star}\end{array}$ \\
\hline
\end{tabular}

Significant results for patients with psoriatic arthritis $v$ controls: ${ }^{\star} \mathrm{p}<0.05 ;{ }^{\star \star} \mathrm{p}<0.01$.

tended to be greater for patients than controls, but in no case was this significant.

LIPOPROTEIN SUBFRACTION COMPOSITION

Thirteen patients with active joint disease, randomly selected from the group of 20 patients, were further studied to determine their lipoprotein subfraction composition. Their initial profiles were similar to the 20 patients with active disease (data not shown). Their mean age was 37 years (range 20-59). HDL cholesterol was again significantly reduced compared with controls (1.09 $v 1.41 \mathrm{mmol} / \mathrm{l}$; $\mathrm{p}<0.005)$.

On analysing LDL subfraction constituents (table 3) the major difference between patients with psoriatic arthritis and controls was an increase in all components of $\mathrm{LDL}_{3}$. There were significantly greater concentrations of total cholesterol, in both its free and esterified forms, triglyceride, phospholipid, and protein in $\mathrm{LDL}_{3}$. Thus the total mass of LDL (lipid + protein) and $\mathrm{LDL}_{3}$ :total $\mathrm{LDL}$ mass ratio was significantly greater in psoriatic arthritis than in controls (table 3 ). Thus there was a greater percentage of $\mathrm{LDL}_{3}$ in the total LDL in patients with psoriatic arthritis $(24.8 \%)$ than in controls $(15.5 \%)$ ( $t$ test, $\mathrm{p}<0.001)$. The mean ratio of $\mathrm{LDL}_{3}: \mathrm{LDL}_{2}$, which further illustrates the value of small dense particles, was more than twice as great in the patients than in the controls ( 0.46 versus 0.22$)$.

We next analysed the proportions of the various components making up the LDL lipoprotein subfractions. All components within $\mathrm{LDL}_{3}$ were uniformly increased with no disproportion compared with controls, apart from an increase in phospholipids. However, there was significantly less cholesterol in $\mathrm{LDL}_{1}$ and $\mathrm{LDL}_{2}$ in patients than in controls and a concomitantly greater percentage of triglyceride in $\mathrm{LDL}_{2}$.

There were no significant differences between patients and controls in the total mass of $\mathrm{VLDL}_{1}, \mathrm{VLDL}_{2}$, or VLDL $\mathrm{VL}_{3}$ subfractions or in the concentration of their constituents, but there were some significant differences in the percentage composition of the various constituents. There was a trend for the triglyceride, cholesterol, and phospholipid concentrations in VLDL and its total mass to be increased compared with controls (table 3 ). The mean proportion of $\mathrm{VLDL}_{1}$ in total VLDL was $22.3 \%$ versus $16.5 \%$ for controls. Also, the percentage of triglyceride in $\mathrm{VLDL}_{3}$ was significantly reduced in the patients compared with controls, and there was a trend for an increase in the percentage of triglyceride in VLDL $_{1}$.

The chylomicron phospholipid concentration was significantly less in psoriatic arthritis than controls (table 3 ), which was reflected in a significant decrease in the percentage composition of phospholipid in chylomicrons.

\section{LP(A) LIPOPROTEIN}

There were no significant differences in $\mathrm{Lp}(\mathrm{a})$ lipoprotein levels in patients with psoriatic arthritis and controls (median $174 \mathrm{mg} / 1$ (range 10-800) v $157 \mathrm{mg} / 1$ (range 10-800)). When the patients with active synovitis were analysed separately, $\mathrm{Lp}$ (a) lipoprotein levels were found to be increased (median $187 \mathrm{mg} / \mathrm{l} v 88 \mathrm{mg} / \mathrm{l}$ ), but this did not reach statistical significance (Mann-Whitney U test). Also, 25\% of patients with psoriatic arthritis had $\mathrm{Lp}(\mathrm{a})$ lipoprotein levels greater than $300 \mathrm{mg} / \mathrm{l}$ compared with $19 \%$ of the controls, though the difference in the proportion was not significantly different. A power calculation indicates that 360 patients and controls would be required to gain a significant difference in the proportion of patients and controls with an $\mathrm{Lp}$ (a) lipoprotein of greater than $300 \mathrm{mg} / \mathrm{l}$. There were weak positive correlations between $\mathrm{Lp}$ (a) lipoprotein levels and ESR (Pearson's $r=0.27, \mathrm{p}=0.098$ ), plasma viscosity $(r=0.27)$, and CRP $(r=0.18)$.

\section{Discussion}

A pattern of dyslipidaemia similar to that found in RA has been reported in patients with psoriatic arthritis. Lazarevic et al studied 40 patients with psoriatic arthritis and found decreased concentrations of total lipids, total cholesterol, cholesterol in LDL, and cholesterol in HDL, which normalised with a reduction in disease activity. ${ }^{5}$ In our study we also found significantly reduced total cholesterol, LDL cholesterol, and HDL cholesterol, and a generalised suppression of total cholesterol, LDL and HDL cholesterol was most apparent in those patients with active joint disease. In addition, $\mathrm{LDL}_{3}$ total mass and its cholesterol and triglyceride components were 
significantly raised, and there was a tendency for $\mathrm{Lp}$ (a) lipoprotein to be increased. Neither of the lipid particles $\mathrm{LDL}_{3}$ or $\mathrm{Lp}(\mathrm{a})$ lipoprotein have been previously studied in psoriatic arthritis.

Psoriasis alone may affect serum lipid levels, though usually only when severe, which was not the case in the current study. ${ }^{17}$ The effect of hormone replacement therapy, taken by seven of the controls, and NSAIDs, taken by 48 of the patients, requires discussion. Oestrogens tend to increase HDL cholesterol, reduce LDL cholesterol, especially small dense $\mathrm{LDL}\left(\mathrm{LDL}_{3}\right.$ in this study) and may reduce $\mathrm{Lp}$ (a) lipoprotein $^{18}$; progesterones tend to have the opposite effect. This might have had a small impact on the comparative data for the total group of 50 patients; however, we found a similar pattern with the controls for the 13 patients included in the ultracentrifuge study, in whom hormone replacement therapy was not a confounding factor. NSAIDs are not reported to affect lipid or lipoprotein levels but may have a minor effect on the acute phase response.

The decrease in total LDL cholesterol seen in our study group may imply protection from atherosclerosis. However, patients with active psoriatic arthritis had a significant shift in distribution towards the smallest, most dense particles of $\mathrm{LDL}\left(\mathrm{LDL}_{3}\right)$, with normal or low levels of $\mathrm{LDL}_{1}$ and $\mathrm{LDL}_{2}$. $\mathrm{LDL}_{3}$ constituted $24.8 \%$ of the total LDL for the patients compared with $15 \%$ for the controls. These findings are clinically relevant because high levels of $\mathrm{LDL}_{3}$, in comparison with the levels of $\mathrm{LDL}_{1}$ and $\mathrm{LDL}_{2}$, are strongly associated with atherosclerosis in population studies. ${ }^{11}$ A similar pattern has been reported in non-insulin dependent diabetes mellitus, in which LDL cholesterol may be normal or reduced in association with excess small dense $\mathrm{LDL}_{3}$ and low HDL cholesterol. ${ }^{19}{ }^{20}$ The shift in LDL composition is much more marked in diabetes mellitus, where the percentage of $\mathrm{LDL}_{3}$ in total LDL may reach $40 \%$. In diabetes the shift is associated with hypertriglyc-

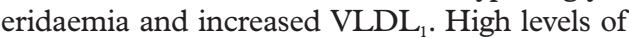
VLDL $_{1}$ may be more slowly catabolised, particularly if there is reduced lipoprotein lipase activity. High levels of $\mathrm{VLDL}_{1}$ encourage increased neutral lipid transfer of cholesterol ester from HDL and LDL to VLDL, in exchange for triglyceride, leading to small dense $\mathrm{LDL}\left(\mathrm{LDL}_{3}\right)$. In the current study there were no significant differences in the total triglyceride levels or the concentration of VLDL subfractions compared with controls; however, there was a trend for a slightly greater proportion of $\mathrm{VLDL}_{1}$ in relation to $\mathrm{VLDL}_{2}$ and $\mathrm{VLDL}_{3}$, which suggests that the postulated mechanism in diabetes may be operating to some extent in active psoriatic arthritis. Small dense LDL has also been linked to increased hepatic triglyceride lipase and it would be of value to measure this in a further study. ${ }^{21}$

The combination of a low HDL cholesterol and a high $\mathrm{LDL}_{3}$, found in the current study, is strongly associated with an increased risk of atherosclerosis in population studies. ${ }^{22}$ Both subfractions of HDL were reduced compared with controls in this study, but only the depression of $\mathrm{HDL}_{3}$ reached statistical significance.
$\mathrm{HDL}_{3}$ is thought to be less "athero-protective" than $\mathrm{HDL}_{2}$, so its increased suppression in relation to $\mathrm{HDL}_{2}$ has less relevance to the cardiovascular risk.

There are a number of mechanisms whereby increased $\mathrm{LDL}_{3}$ may cause atherosclerosis. $\mathrm{LDL}_{3}$ becomes rapidly oxidised and has an enhanced ability to cross cell surfaces, where it may be directly toxic to endothelium. The clearance of $\mathrm{LDL}_{3}$ from the circulation by the LDL receptor mechanism may also be impaired, making more LDL available for removal by the atherogenic scavenger pathway. ${ }^{23}$ In the arterial wall, the resulting lipid-rich macrophages become foam cells that accumulate in early atheromatous lesions. An association between the susceptibility of LDL to oxidation in vitro and the extent of atherosclerosis of coronary vessels has been demonstrated. ${ }^{24}$

$\mathrm{Lp}$ (a) lipoprotein is an independent risk factor for atherosclerosis and thrombosis, with values above $300 \mathrm{mg} / \mathrm{l}$ associated with a twofold increased risk of myocardial infarction $^{12}$ and an accelerated progression of coronary atheroma. ${ }^{13}$ Its mode of action is thought to be related to homology with plasminogen, resulting in inhibition of fibrinolytic activity and increasing the likelihood of thrombosis. Increased levels of $\mathrm{Lp}(\mathrm{a})$ lipoprotein have been reported in RA, where it may behave as an acute phase protein. ${ }^{14}$ NSAIDs may have a modest effect of reducing the $\mathrm{Lp}$ (a) lipoprotein by reducing the acute phase response. Our results show a similar pattern to that reported in $\mathrm{RA}$, with a slight increase in $\mathrm{Lp}$ (a) lipoprotein levels and weak positive correlations with inflammatory markers. A power calculation indicates that 360 patients and controls would be needed to produce a significant proportional increase in $\mathrm{Lp}$ (a) lipoprotein in patients compared with controls.

Lipoproteins exist as packages containing predominantly cholesterol, triglyceride, and apolipoproteins. The synthesis and catabolism of each constituent can proceed independently of the other contents of the package, though a certain amount of covariance exists. LDL cholesterol and triglyceride may be high or low, without any change or with an opposing change in apolipoprotein concentration. Apolipoprotein A I is the predominant apolipoprotein in HDL, comprising $60 \%$ of the protein mass, and apolipoprotein B is the predominant apolipoprotein in LDL and VLDL, comprising $90 \%$ of the protein mass of LDL. LDL and VLDL have one apolipoprotein per lipoprotein package, so apolipoprotein concentration is an indication of the number of particles present. Lower apolipoprotein A I and high apolipoprotein B have been found in association with coronary artery disease. The apolipoproteins A I and B in the patients with psoriatic arthritis were not significantly different from those in controls, though they tended to be lower in the active group, perhaps partly reflecting the generalised reduction in cholesterol and cholesterol associated lipids. This notion is supported by the apolipoprotein A I:HDL cholesterol and apolipoprotein B:LDL cholesterol ratios, which tended to be greater in the patients than controls, reflecting a 
greater relative suppression of HDL cholesterol than apolipoprotein A I and of LDL cholesterol than apolipoprotein B.

There are a number of reasons why dyslipidaemia may be associated with an active inflammatory arthritis. An increased production of acute phase proteins by the liver in inflammation may occur at the expense of lipoprotein production, thereby tending to reduce lipoprotein levels. ${ }^{2}$ Enhanced reticuloendothelial system uptake of lipoproteins in chronic inflammation may occur, which is compatible with an accelerated atherosclerotic process at the vessel wall. ${ }^{6}$ Mediators of inflammation, such as the interferons $(\alpha, \beta, \gamma), \mathrm{CRP}$, and the proinflammatory cytokines, interleukin 1 and tumour necrosis factor $\alpha$, produced by macrophages have been shown to suppress lipoprotein lipase activity and increase oxidative metabolism. ${ }^{25-31}$ Reduced levels of the antioxidant selenium have also been found in psoriatic arthritis. $^{32}$

It is likely that a combination of factors related to the systemic inflammatory response may operate in psoriatic arthritis to produce the observed pattern of dyslipoproteinaemia.

A reported increase in occlusive vascular disease in psoriasis has led to various studies of lipids and lipoproteins, with conflicting results. ${ }^{17}$ Hypercholesterolaemia or hypertriglyceridaemia, or both, may occur, which contrasts with the findings in psoriatic arthropathy. Apolipoprotein B has been reported to be low, unchanged, or increased in different studies. ${ }^{17}{ }^{33}$ However, an increased prevalence of hypertension, diabetes mellitus, impaired glucose tolerance, and hyperuricaemia, all of which are known to be associated with dyslipoproteinaemia, is associated with psoriasis and may not have been adequately controlled in some studies. In addition the severity of psoriasis may affect the results. ${ }^{17}$ None of our patients had severe skin disease (defined as a PASI score of greater than 30) at the time of the study, making it unlikely that psoriasis itself contributed to our findings.

To conclude, this is the first report documenting high levels of $\mathrm{LDL}_{3}$ in relation to total LDL in an inflammatory form of arthritis. Lipoprotein subfractions and $\mathrm{Lp}$ (a) lipoprotein warrant further investigation in a larger group of patients with psoriatic arthritis, with the inclusion of hepatic triglyceride lipase measurement, and longitudinal data. Lipoprotein composition also warrants investigation in RA, where the increased mortality from atherosclerosis is more clearly established. In patients with a pattern of low HDL, high $\mathrm{LDL}_{3}$, and high LP(a) lipoprotein, long term follow up is needed to determine the predictive risk of macrovascular disease.

The work was supported by a research and development grant from the Wessex Regional Health Authority. Dr Jones was supported by the Sir Jules Thorn Charitable Trust.

1 Pincus T. Long-term outcomes in rheumatoid arthritis. Br J Rheumatol 1995;34(suppl):59-73.

2 London MG, Muirden KD, Hewitt JV. Serum cholesterol in rheumatic disease. BMJ 1963;1:1380-3.
3 Rossner S, Lofmark C. Dyslipoproteinaemia in patients with active, chronic polyarthritis. A study on serum ipoproteins and triglyceride clearance (intravenous fat tolerance test) Atherosclerosis 1977;28:41-52.

4 Lorber M, Aviram S, Linn S, Scharf Y, Brook JG. Hypocholesterolaemia and abnormal high density lipoprotein in rheumatoid arthritis. Br J Rheumatol 1985;24:250-5.

5 Lazarevic MB, Vitic J, Mladenovic V, Myones BL, Skosey JL, Swedler WI. Dyslipidaemia in the course of active rheumatoid arthritis. Semin Arthrits Rheum 1992;22:17280 .

6 Svenson KLG, Lithell H, Hallgren R, Selinus I, Vessby B. Serum lipoprotein in active rheumatoid arthritis and other 147:1912-16.

7 Winyard PG, Tatzbar F, Esterbauer H, Kus ML, Blake DR, Morris CJ. Presence of foam cells containing oxidised low density lipoprotein in the synovial membrane from patients with rheumatoid arthritis. Ann Rheum Dis 1993;52:677-80.

8 Wong K, Gladman DD, Husted J, Long J, Farewell V. Mortality studies in psoriatic arthritis. Arthritis Rheum 997;40:1867-972.

9 Castelli WP, Garrison RJ, Wilson PWF. Incidence of coronary heart disease and lipoprotein cholesterol levels. JAMA 1986;256:2835

10 Lindgren FT, Jewson LC, Hatch FT. The isolation and quantitative analyses of serum lipoproteins. In: Nelson GJ, ed. Blood lipids and lipoproteins; quantitation, composition and metabolism. Vol 5. New York: Wiley Interscience, 1972:182274.

11 Brunzell JD, Hokanson JE. Low-density and high density lipoprotein subspecies and risk for premature coronary artery disease. Am J Med 1999;107:165-85.

12 Rosengren A, Wilhelmsen L, Eriksson E, Risberg B, Wedel $\mathrm{H}$. Lipoprotein(a) and coronary artery disease: a prospective case-controlled study in a general population sample of middle-aged men. BMJ 1990;301:1248-51.

13 Terres W, Tatsis E, Pfalzer B, Beil U, Beisiegel U, Hamm CW. Rapid angiographic progression of coronary heart disease in patients with elevated lipoprotein(a). Circulation ease in patients with

14 Maher VMG, Brown BG. Lipoprotein (a) and coronary heart diseases. Curr Opin Lipidol 1995;6:229-35.

15 Rantapaa-Dahlqvist S, Walberg-Jonsson S, Dahlen G. Lipoprotein (a), lipids, and lipoproteins in patients with rheumatoid arthritis. Ann Rheum Dis 1991;50:366-8.

16 Camp RDR. Psoriasis. In: Champion RH, Burton J L, Ebling FJG, eds. Textbook of dermatology. 5 th ed. Oxford: Blackwell, 1992:1391-458.

17 Seishima M, Mori S, Noma A. Serum lipid and apolipoprotein levels in patients with psoriasis. Br J Dermatol 1994;130:737-42.

18 Sansioe G. Cardioprotection of estrogens: mechanisms of action-the lipids [review]. International Journal of Fertility and Menopausal Studies. 1994;39(suppl 1):43-9.

19 James RW, Marini M, Ruiz J, Pometta D. Factors influencing the low density lipoprotein profile in type II diabetic ing the low density lipoprotein prof
patients. Diabet Med 1994;12:61-5.

20 Barrett-Connor E, Witztum JL, Holdbrook M. A community study of high density lipoproteins in adult non-insulinnity study of high density lipoproteins in adult non-insulin-
dependent diabetics. Am J Epidemiol 1983;1 17:186-92.

21 Zambon A, Austin MA, Brown BG, Hokanson JD, Brunzell JD. Effect of hepatic lipase on LDL in normal men and those with coronary artery disease. Arterioscler Thromb 1993;13:147-53.

22 Regnstron J, Nilsson J, Tornwall P, Landdou C, Hamsten A. Susceptibility to low density lipoprotein oxidation and coronary atherosclerosis in man. Lancet 1992;339:883-7.

23 Nigon F, Lesnik P, Rouis M, Chapman MJ. Discrete subspecies of human low density lipoproteins are heterogeneous in their interaction with the cellular LDL receptor. J Lipid Res 1992;32:1741-53.

24 Campos H, Genest J, Blijlevan SEM, McNamara JR, Jenner $\mathrm{JL}$, Ordaowas JM, et al. LDL particle size and coronary $\mathrm{JL}$, Ordaowas JM, et al. LDL particle size and coron
artery diseases. Arterioscler Thromb 1992;12:187-95.

25 Ilowite NT, Samuel P, Ginzler E, Jocobson MS. Dyslipoprollowite NT, Samuel P, Ginzler E, Jocobson MS. Dyslipopro-
teinemia in paediatric SLE. Arthritis Rheum 1988;31:85962 .

26 Ogawa H, Nielson S, Kawakami M. TNF and IL-1 show different modes of combined effect on LP activity and intracellular lipolysis in 3T3-L1 cells. Biochem Biophys Acta 1989;1003:131-5.

27 Spriggs DR, Sherman M L, Michie H, Arthur KA, Imamura $\mathrm{K}$, Wilmore $\mathrm{D}$, et al. Recombinant human TNF administered as a 24-hour infusion. J Natl Cancer Inst 1988;80: 1039-44.

28 Fried SK, Zechner R. TNF decreases human adipose tissue LPL mRNA levels, synthesis and activity. J Lipid Res 1989; 30:1917-23

29 Beutler BA, Cerami A. Recombinant interleukin-1 suppresses lipoprotein lipase activity in 3T3-L1 cells. J Immunol 1985;135:3969-971.

30 Rosenzweig IB, Wiebe DA, Borden EC, Stoner B, Shrago ES. Plasma lipoprotein changes in humans induced by beta interferon. Atherosclerosis 1987;647:261-7.

31 Rowe IF, Soutar AK, Trayner IM. Circulating human C-reactive protein binds very-low-density lipoproteins. C-reactive protein binds very-low-
Clin Exp Immunol 1984;53:237-44.

32 Azzini M, Girelli D, Olivieri O, Guarini P, Stanzial AM, Azzini M, Girelli D, Olivieri O, Guarini P, Stanzial AM,
Frigo A, et al. Fatty acids and antioxidant micronutrients in psoriatic arthritis. J Rheumatol 1995;22:103-8.

33 Brustein DM, Scher RK, Auerbach R. Hyperlipoproteinaemia and psoriasis. Lancet 1976;1:154 